\title{
Sınıf Öğretmenlerinin İnterneti Eğitim Amaçlı Kullanma Durumları*
}

\section{Sultan Selen KULA**, Mutlu Pınar DEMIRCİ GÜLER ${ }^{* * *}$}

Öz: Sınıf öğretmenlerinin eğitim aracı olarak interneti kullanma durumlarının betimlendiği bu çalışma tarama modelinde nitel bir çalışmadır. Veri toplama aracı olarak araştırmacılar tarafından geliştirilen yarı yapılandırılmış görüşme formu, 2016-2017 öğretim yılında Amasya İli’nde görev yapmakta olan 29 kişilik çalışma grubuna uygulanmış, elde edilen veriler betimsel analize tabi tutulmuştur. Çalışma sonucunda, araştırma grubunda yer alan sınıf öğretmenlerinin tamamı öğretimin çeşitli süreçlerinde internet kullandıklarını ve ders hazırlıklarında en çok yararlandıklerı internet sitesinin egitimhane.com olduğunu ifade etmişlerdir. $\mathrm{Bu}$ durumun sebeplerini, internet kullanımının öğrencilerin bilgi düzeylerinde kalıcılığı sağlaması, dikkatlerini, derse yönelik ilgilerini, akademik başarılarını ve motivasyonlarını arttırması, öğrenme sürecine aktif katılımın sağlanması, daha fazla bilgi kaynağının erişimine olanak tanıması ve öğretmenin farklı öğretim yöntemlerini kullanabilmesini kolaylaştırması olarak ifade etmişlerdir. Bunun yanı sıra sınıf öğretmenleri, derslerde interneti kullanma konusunda birtakım endişeler de taşımaktadır. İnternet kullanımının öğrenciye vakit kaybettirme, dersten uzaklaştırma, dikkat dağıtıcı olma, internette çocuklara kötü örnek oluşturabilecek içeriklerin olması, aktif öğrenmeye engel oluşturma, göz sağlı̆̆ını olumsuz etkileme ve çocukları hazıra alıştırma gibi olumsuz birtakım etkiler olabileceği kaygısı dikkat çekmektedir.

Anahtar Kelimeler: Sınıf öğretmeni, İnternet, Eğitim amaçlı internet, Öğretim süreci.

\section{Internet Usage of Classroom Teachers for Educational Purposes}

Abstract: The purpose of this study is to determine the state of internet usage of classroom teachers. In line with this goal, the study group consists of 29 classroom

\footnotetext{
* Bu çalışma 26-28 Ekim 2017 tarihinde gerçekleştirilen 3. Uluslar arası Sosyal Bilimler Sempozyumu’nda (Kahramanmaraş) sözlü bildiri olarak sunulmuştur.

** Arş. Gör. Dr., Ahi Evran Üniversitesi, Eğitim Fakültesi, Eğitim Programları ve Öğretim, Email: selenyazgunoglu@windowslive.com, Orcid No: 0000-0002-1614-3431.

*** Doç. Dr., Ahi Evran Üniversitesi, Eğitim Fakültesi, Temel Eğitim Bölümü, Email:pinarguler@ahievran.edu.tr Orcid No: 0000-0002-8286-4472.
}

\begin{tabular}{lll}
\hline Gönderim:25.12.2018 Kabul:15.02.2019 $\quad$ Yayın:05.04.2019
\end{tabular}


teachers who are working in Amasya/ Turkey during the 2016-2017 academic year. The study was designed in a survey model and was conducted using qualitative research method. Semi-structured interview form was used as data collection tool. The obtained data were analyzed with descriptive analysis technique. On the basis of findings obtained from the study, it is seen that every classroom teacher participated in the study is using the internet, the most used website in course preparations is egitimhane.com, the use of internet makes the information permanent, increases the students' attention, increases their interest in the lesson, increases academic success and motivation, provides easy access to more information sources, allows the teacher to use different teaching methods in the lesson, and enables active participation of students in the learning process. In addition, classroom teachers have some concerns about using the internet in lessons. It is noteworthy that the use of the internet may have negative effects such as wasting time, removing it from the course, distracting the students, having content that can be a bad example for children on the internet, preventing the active learning, negatively affecting the eye health and accessing students to information without effort.

Keywords: Classroom teacher, Internet, Internet for educational purposes, Learningteaching process.

\section{Giriş}

Yirmi birinci yüzyılın en önemli icatlarından biri sayılan internet, bilgisayarların birbirine bağlanması ile oluşan dünyanın en büyük iletişim ağı ve bilgi bankasıdır. İnternet, haberleşme, karşılıklı görüşme, kaynak paylaşımı ve bilgiye erişim süreçlerini son derece kolaylaştırmış (Şahan, 2011), kablosuz bağlantı imkânları ve taşınabilir cihazların kullanıma sunulması ile de eğitim alanında öğretmenlerin öğretim sürecinde faydalandıkları bir teknoloji olmuştur (Schunk, 2014). Günümüzde öğretmenler interneti, dersi planlama, öğretme-öğrenme yöntemlerini düzenleme ve öğretimi değerlendirme gibi öğretimin her sürecinde dâhil edebilmektedir. Eğitim süreçlerinde internetten yararlanmanın öğrenciler üzerindeki olumlu etkileri Ogle ve Beers (2009) tarafından şöyle ifade edilmiştir (Akt: Borich, 2014):

- öğrencinin motivasyon ve ilgisini arttırma

- okuma ve yazma becerilerini geliştirme

- sınıf içi okuma materyallerini geliştirme 
- cevap verme ve iş birliği yapma firsatlarını arttırma

- deneyim ve içerik bilgisini geliştirme

- hayal kurma, eleştirel düşünme ve problem çözme becerilerini geliştirme

- çok kültürlü anlayışı teşvik etme

- öğrencilerin bireysel farklılıklarını dikkate alma

- yeni okuryazarlık becerilerini anlama ve kullanımını yaygınlaştırma

- profesyonel gelişim ve iş birliğini teşvik etme şekilnde ifade edilmiştir.

Yukarıdaki özellikleri dolayısı ile eğitimde internet kullanımı amacıyla ülkemizde 2002 yılı sonuna kadar Temel Eğitim Projesi kapsamında tüm ilköğretim okullarının ağ ile donatılması planlanmıştır (Akkoyunlu, 2002). Girişimlerde Bilişim Teknolojileri Kullanımı araştırmasında İnternet Erişimi oranları incelendiğinde 2005 yılında \%80,4 oranında internet erişimi sağlanırken, 2016 yılında bu rakamın \%93,7'ye yükseldiği görülmektedir. Milli Eğitim Bakanlığı (MEB) tarafından 2011 yılında hayata geçirilen Fırsatları Artırma ve Teknolojiyi İyileştirme Hareketi (FATİH) Projesi, eğitim ve öğretimde fursat eşitliğini sağlamak ve okullardaki teknolojiyi iyileştirmek amacıyla, bilişim teknolojileri araçlarının öğrenme-öğretme sürecinde daha fazla duyu organına hitap edilecek şekilde derslerde etkin kullanımını sağlamayı hedeflemiştir (MEB, 2018). $\mathrm{Bu}$ proje kapsamında eğitim ortamlarında tam verimle teknolojinin ve internetin kullanılabilmesi amaçlanmıştır. Bu çalışmaların sonuç verdiği ve günümüzde genel olarak çoğu okulda internet erişiminin sağlandığı ifade edilebilir. Amerika'daki devlet okullarında ise 1994 yılından itibaren internet erişiminde hızlı bir artış olduğu, 1998 yılında okulların \%90'ında, 1999'da ise okulların \%99'unda internet erişiminin bulunduğu, 2000'li yıllara gelmeden hemen hemen tüm okullarda internet erişimine imkân sağlandığı görülmüştür (Becker, 1999; NCES, 2000).

Okullarda internet kullanımı sürecinde önemli olan faktörlerden biri de öğretmenlerin bu teknolojileri kullanabilen ve kullanımını yayabilen niteliklerle donanmış olmaları ve gerek sınıf içinde, gerekse sınıf dışında eğitim amaçlı etkinlikleri düzenlerken internet kullanımına ilişkin sahip oldukları öz yeterlik inançlarıdır. Baş (2011) tarafından sınıf öğretmenleri ile yürütülen çalışma sonuçlarına göre, eğitsel amaçlı internet kullanımı konusunda sınıf öğretmenlerinin kendilerini oldukça yeterli gördükleri bulgulanmıştır. Bunun yanı sıra son yıllarda öğrencilerin, interneti eğitsel amaçlı olarak öğretmenlerden daha fazla kullandıkları yönünde çalışma sonuçları da bulunmaktadır 
(Kimmons, Clark ve Lim, 2017). Bu sonuçtan hareketle, genç neslin eğitim amaçlı olarak internet kullanımında öğretmenlerden daha aktif oldukları ifade edilebilir. Genç nesillerin interneti aktif bir biçimde kullanmasının olumlu pek çok yönünün yanı sıra internetin, böylesine yaygın ve bazen de bilinçsiz kullanımı birçok riski de beraberinde getirmektedir. Özellikle bilgi ve iletişim teknolojilerinin çocuklar tarafından denetimsiz kullanımları bu riskleri artırmaktadır. Çocukların yaşlarına uygun olmayan şiddet, korku veya cinsellik içeren içeriklere maruz kalmaları söz konusu durumlardandır (Erdur-Baker ve Kavşut, 2007). Bunların yanı sıra, çağımızın önemli sorunlarından biri haline gelen video ve bilgisayar oyun bağımlılığı, teknoloji kullanımıyla ilgili riskler arasında ilk sıralarda yerini almaktadır. Bilgisayar ve oyun bağımlılığı özellikle çocuklar ve gençler için tüm dünyada hızla yaygınlaşan bir halk sağlığı sorunu halini almıştır (Gentile vd, 2017; Wu, Chen, Tong, Yu ve Lau, 2018). Bu bağlamda öğretmenlerin öğrencilerini, interneti eğitsel amaçlı kullanmaya özendirmenin bu alandaki riskli durumlara karşı önleyici bir özelliği olduğunu söylemek mümkündür (Kaşıkçı, Çağıltay, Karakuş, Kurşun ve Ogan, 2014).

Türkiye'de, Milli Eğitim Bakanlığı bünyesinde Öğretmen Yetiştirme ve Eğitimi Genel Müdürlüğü koordinatörlüğünce tanımlanan "Öğretmenlik Mesleği Genel Yeterlikleri” kapsamında da "öğrenme ortamlarını etkili bir şekilde düzenleyebilme”, öğretmenlerde bulunması gereken önemli yeterliklerden birisi olarak tanımlanmaktadır. $\mathrm{Bu}$ bağlamda öğretmenlerden teknoloji kaynakları içinde en yaygın kullanım alanı olan interneti etkili kullanmaları ve internetin etkili kullanımını öğrencilere de kazandırmaları beklenmektedir. İnternetin öğrenme ortamlarında kullanımının yaygınlaşması, öğrenci ve öğretmen arasındaki etkileşimi, ilişkiyi yeniden biçimlendirmiştir. İnternet kullanımının hızla artması, bilgiye ulaşımı kolaylaştırmıştır. Dolayısıyla öğretmenin rolü her şeyi bilen, bilgiyi aktaran bir yapıdan, öğrencilerini bilgiye ulaşmaya yönlendiren, bu konuda onlara rehberlik eden bir yapıya dönüşmüştür (Akkoyunlu, 2002). Sınıf öğretmenlerine ilişkin alan yeterlikleri (ÖYEGM, 2008) arasında, "Bilişim teknolojilerinden mesleki gelişim ve iletişim için yararlanabilme” ayrıca öğrencilerin bilim ve teknolojik kavramları doğru ve etkin kullanabilmesini sağlama ile ilgili pek çok yeterlik alanı yer almaktadir.

Okullarda en yaygın kullanılan bilişim teknolojisinin internet olduğu düşünüldüğünde, Türkiye'de, öğretmenlerin interneti etkin bir biçimde kullanmalarının 
yanı sıra öğrencilere de doğru ve etkin kullanmaları yönünde liderlik etmelerinin beklendiği görülmektedir. Bu doğrultuda araştırmanın amacı şu şekilde belirlenmiş̧tir:

\section{Araştırmanın Amacı}

$\mathrm{Bu}$ araştırmanın amacı, sınıf öğretmenlerinin eğitim sürecinde internet kullanım durumlarını betimlemektir. $\mathrm{Bu}$ amaç doğrultusunda araştırmanın alt problemleri şu şekilde belirlenmiştir:

1. Sınıf öğretmenlerinin interneti kullanım amaçları nelerdir?

2. Sınıf öğretmenlerinin ders hazırlıklarını yaparken yararlandıkları web siteleri nelerdir?

3. Sınıf öğretmenlerinin, derslerde internet kullanımına ilişkin olumlu görüşleri nelerdir?

4. Sınıf öğretmenlerinin, derslerde internet kullanımına ilişkin olumsuz görüşleri nelerdir?

5. Sınıf öğretmenleri internet kullanım düzeyleri mi bakımından kendilerini nasıl değerlendirmektedir?

6. Sınıf öğretmenleri internet kullanımı bakımından erişim olanaklarını nasıl değerlendirmektedir?

7. Sınıf öğretmenlerinin, internet kullanım imkânlarına ilişkin okullarından beklentileri nelerdir?

\section{Yöntem}

Çalışma tarama modelinde, nitel bir çalışmadır. Tarama modeli, var olan durumları olduğu gibi ortaya koymaya yarayan; olgulara, durumlara müdahale etmeden betimlemeyi amaçlayan araştırmalarda kullanılan bir araştırma modelidir (Kaptan, 1973; Sönmez ve Alacapınar, 2011). Nitel yöntem ise derin ve ayrıntılı konularda çalışarak o konuya ilişkin derinlemesine bilgi edinmeyi sağlamaktadır (Patton, 2014). Çalışma, nitel araştırma desenlerinden durum çalışması deseninde tasarlanmıştır. Durum çalışması deseninde, bir duruma ilişkin etkenler derinlemesine bir yaklaşımla ele alınır ve ilgili durumu nasil etkiledikleri veya etkilendikleri konusuna odaklanılır (Merriam, 2013; Yıldırım ve Şimşek, 2008). Bu bağlamda çalışmada, sınıf öğretmenlerinin eğitim amaçlı 
olarak interneti kullanmaları bir durum olarak değerlendirilmiş ve alt problemler doğrultusunda incelenmiştir.

\section{Çalışma Grubu}

Araştırmanın çalışma grubunu 2016-2017 öğretim yılında Amasya İli’nde görev yapmakta olan 29 sınıf öğretmeni oluşturmuştur. Türkiye İstatistik Kurumu tarafından 2015 yılında "İllerde Yaşam Endeksi” çalışması kapsamında, bireylerin topluma ve ekonomiye verimli bir şekilde katılması için gerekli bilgi, beceri ve yeterliliklerin sağlanmasında büyük öneme sahip eğitim boyutu endeksinde Amasya İli'nin üçüncü sırada yer aldığı görülmektedir. Bu sonuçtan yola çıkarak araştırmanın Amasya İli’nde yürütülmesine karar verilmiştir. Örneklem seçimi, amaçlı örnekleme yöntemlerinden kritik durum örneklemesi yoluyla belirlenmiştir (Yıldırım ve Şimşek, 2008). Kritik durum örneklemesinde "bu grup belirli bir problemle karşılaşlyorsa, diğer bütün gruplar kesinlikle bu problemle karşı karşıya kalır. ”şeklinde bir yargı söz konusudur (Yıldırım ve Şimşek, 2008). İstatistik Kurumu tarafından eğitim endeksi sıralamasında üst sırada yer alan Amasya İli'nde görülen birtakım olumsuzluklar diğer iller için de görülebilme ihtimali yüksek olarak kabul edilebilir. Katılımcılara ilişkin betimsel veriler Tablo1'de sunulmuştur.

Tablo 1. Cinsiyete, Kıdeme ve Çalışılan Sınıf Düzeyine İlişkin Betimsel Bilgiler

\begin{tabular}{lll}
\hline Cinsiyet & $\mathbf{n}$ & $\mathbf{\%}$ \\
\hline Kadın & 18 & 62 \\
Erkek & 11 & 38 \\
Toplam & 29 & 100 \\
\hline Kıdem & $\mathbf{n}$ & $\mathbf{\%}$ \\
\hline $1-5$ Yıl & 1 & 3,4 \\
$6-10$ Yıl & 5 & 17,2 \\
$11-15$ Yıl & 7 & 24,1 \\
$16-20$ Yıl & 6 & 20,6 \\
20 Yıl ve Fazlası & 10 & 34,7 \\
Toplam & 29 & 100 \\
\hline Çalışılan Sınıf Düzeyi & $\mathbf{n}$ & $\mathbf{\%}$ \\
\hline 1. Sınıf & 8 & 27,5 \\
2. Sınıf & 9 & 31 \\
3. Sınıf & 8 & 27,5 \\
4. Sınıf & 9 & 31 \\
Toplam & 29 & 100 \\
\hline
\end{tabular}

Tablo 1'de görüldüğü gibi katılımcıların \%62'si (f=18) kadın, \%38'i (f=11) erkeklerden oluşmaktadır. Katılımcıların çoğunluğu ( $\mathrm{f}=10)$ mesleki kıdem olarak 20 yıl 
ve daha fazla süredir çalışmaktadır. 1-5 yıl arası kıdeme sahip olan yalnızca bir kişi bulunmaktadır. Bu durum merkez okullarda görev yapan sınıf öğretmenlerinin, çoğunlukla kıdemi yüksek öğretmenlerden oluştuğu şeklinde yorumlanabilir. Çalışmaya ilkokulun her kademesinde çalışmakta olan sınıf öğretmenleri dâhil edilmiştir.

\section{Veri Toplama Aracı}

Çalışmada, veri toplama aracı olarak yarı yapılandırılmış görüşme formu kullanılmıştır. Yarı yapılandırılmış görüşmeler, katılımcının algıladığı dünyayı kendi düşünceleriyle anlatmasını sağlar (Merriam, 2013). Görüşme formunda çalışmanın alt problemlerini kapsayacak şekilde, sınıf öğretmenlerinin eğitimde internet kullanım durumlarına ilişkin 12 adet soru yer almaktadır. Görüşme formu oluşturulurken ilgili literatür taranmış, taslak sorular oluşturulmuş ve görüşme formunun kapsam geçerliğine ilişkin biri sınıf öğretmenliği, ikisi program geliştirme alanından olmak üzere üç uzmandan görüş alınmıştır. Taslak form oluşturulduktan sonra araştırmada yer almayan üç katılımcı ile deneme uygulaması yapılmış ve formda yer alan sorular yeniden düzenlenmiştir. Uzman görüşleri ve ön uygulamadan elde edilen sonuçlar doğrultusunda sorulara son şekli verilmiştir.

\section{Verilerin Toplanması ve Analizi}

Araştırma verileri, Amasya il merkezinde bulunan iki farklı devlet okulunda çalışmakta olan sınıf öğretmenlerinden görüşme yoluyla toplanmıştır. Araştırmaya başlamadan önce sınıf öğretmenleri, araştırmanın konusu ile ilgili bilgilendirilmiştir. Çalışmaya gönüllülük esası ile katılım sağlanmıştır. Okul yöneticileri tarafından araştırmacılara gösterilen boş bir odada görüşmeler gerçekleştirilmiştir. Katılımcıların görüşleri, araştırmacılar tarafından görüşme formlarına not alınarak kaydedilmiştir.

Sınıf öğretmenlerinin formda yer alan görüşleri betimsel analiz tekniği ile analiz edilmiştir. $\mathrm{Bu}$ amaçla öncelikle bilgisayar ortamına aktarılan tüm veriler kodlanmıştır (Glesne, 2012; Merriam, 2013; Yıldırım ve Şimşek, 2008;). Verilerin kodlanmasıyla, aynı biçimde kodlanan tüm veriler okunarak, o koda ait verilerde nasıl bir görüşün hâkim olduğu bulunmaya çalışılır (Glesne, 2012).

Daha sonra veriler kodlar arasındaki ortak noktalara göre sınıflandırılarak temalara ayrılmıştır. Bu aşamada ortaya çıkan temalar genel bir olguya işaret etmektedir (Yıldırım ve Şimşek, 2008). 
Üçüncü aşamada ise kodlara ve temalara göre sınıflandırılmış veriler düzenlenerek, araştırma problemine uygun şekilde yorumlanmıştır.

Görüme formundan elde edilen nitel verilerin analizinde güvenirliği sağlamak amacıyla kodlayıcılar arası güvenirlik hesaplanmaktadır. Bu hesaplamayla nitel verilerin birden fazla kodlayıcı tarafindan kodlanması ve kodlayıcılar arası uyumun hesaplanarak güvenirliğin sağlanması söz konusu olmaktadır (Creswell, 2013). Miles ve Huberman (1994), kodlayıcılar arası görüş birliğinin hesaplanması için; Görüş birliği/(görüş birliği+görüş ayrılığ 1 )*100 formülü ile hesaplama önermişlerdir. Bu hesaplama ile elde edilen oranın \%80 benzerlikte olmasının kabul edilebilir olduğunu belirtmişlerdir. Bu araştırmada öğretmen görüşmelerinden elde edilen nitel veriler, her iki araştırmacı tarafından kodlanmıştır. İki kodlayıcı tarafından öncelikle birer transkript kodlanmış ardından çapraz kontrol yapılmıştır. Kodlamalarda görülen benzerlik ve farklılıklar karşılaştırılmıştır. Temalara ilişkin her bir kod tartışılmıştır, ortak bir kodlama tablosu oluşturulmuştur. İki kodlayıcı bu ortak tabloya dayalı olarak ayrı ayrı kodlamaya devam etmişlerdir. Kodlayıcılar arası görüş birliğinde yeterli oran elde edildikten sonra $(\% 88,2)$ araştırmacılardan biri ortak tablodan yola çıkarak kodlamaya yalnız devam etmiştir. Yeni kod eklenmesi durumunda diğer kodlayıcı ile tartışılarak fikir birliğine ulaşılmıştır.

Araştırmanın güvenirliğini arttırmak amacıyla toplanan verilerin ayrıntılı olarak rapor edilmesine özen gösterilmiş ve çalışmaya katılan bireylerin görüşlerine doğrudan alıntılarla yer verilmiştir (Yıldırım ve Şimşek, 2008).

\section{Bulgular}

\section{Birinci Alt Probleme İlişkin Bulgular}

Araştırmanın birinci alt problemi sınıf öğretmenlerinin interneti kullanım amaçlarını belirlemektir. Sınıf öğretmenlerinin interneti kullanım amaçlarına Tablo 2'de yer verilmiştir:

Tablo 2. Sınıf Öğretmenlerinin İnterneti Kullanım Amaçları

\begin{tabular}{lll}
\hline İnterneti Kullanım Amacı & f & $\mathbf{\%}$ \\
\hline Öğretimi Planlama ve Yürütme & 29 & 96,5 \\
Bankacılık İşlemleri & 22 & 75,8 \\
E-posta işlemleri & 21 & 72,4 \\
Sosyal Paylaşım Siteleri & 20 & 68,9 \\
Alışveriş̧ & 18 & 62 \\
Haberlerin Takibi & 1 & 3,4 \\
\hline
\end{tabular}


$\mathrm{Bu}$ araştırmaya katılan tüm katılımcılar, farklı amaçlarla da olsa interneti kullandıklarını ifade etmişlerdir. Sınıf öğretmenlerinin interneti en çok öğretimi planlama ve yürütme amacıyla ( $\mathrm{f}=29)$ kullandıkları görülmektedir. Bunun yanı sıra bankacılık işlemleri ( $\mathrm{f}=22)$, e-posta işlemleri $(\mathrm{f}=21)$, sosyal paylaşım sitelerinin kullanımı $(\mathrm{f}=20)$, alışveriş ( $\mathrm{f}=18)$, haberleri takip etme $(\mathrm{f}=1)$ ve ders işleme sırasında kullanma ( $\mathrm{f}=1)$ amacıyla interneti kullanmakta oldukları ifade edilmiştir.

\section{İkinci Alt Probleme İlişkin Bulgular}

Araştırmanın ikinci alt problemi sınıf öğretmenlerinin ders hazırlıklarını yaparken yararlandıkları web sitelerini belirlemektir. Sınıf öğretmenlerinin ders hazırlıklarını yaparken kullandıkları web sitelerine Tablo 3 'te yer verilmiştir:

Tablo 3. Sınıf Öğretmenlerinin Ders Hazırlığı İçin Kullandıkları Web Siteleri

\begin{tabular}{|c|c|c|c|}
\hline Web Siteleri & Katılımcılar & $\mathbf{f}$ & $\%$ \\
\hline http://www.egitimhane.com/ & $\begin{array}{l}\text { k1-k2-k3-k4-k6-k7-k8- } \\
\text { k9-k10-k13-k14-k15-k16- } \\
\text { k17-k18-k19-k21-k22-k24-k25- } \\
\text { k26-k28 }\end{array}$ & 22 & 75,8 \\
\hline https://www.morpakampus.com/ & $\begin{array}{l}\text { k1-k4-k7-k8-k9-k14-k15-k16-k20- } \\
\text { k21-k22-k24-k29 }\end{array}$ & 13 & 44,8 \\
\hline http://www.eba.gov.tr/ & k4-k7-k8-k9-k11-k20-k21-k23 & 8 & 27,5 \\
\hline https://www.okulistik.com/ & k7-k8-k9-k14-k16-k18-k19 & 7 & 24,1 \\
\hline http://www.sorubak.com/ & k7-k25 & 2 & 6,8 \\
\hline http://www.leventyagmuroglu.com/ & k3-k13 & 2 & 6,8 \\
\hline http://www.dersteknik.com/ & k6 & 1 & 3,4 \\
\hline http://www.sinifogretmeniyiz.biz/ & $\mathrm{k} 13$ & 1 & 3,4 \\
\hline http://www.dersimiz.com/ & $\mathrm{k} 27$ & 1 & 3,4 \\
\hline
\end{tabular}

yararlandıkları sitenin "egitimhane.com” $(\mathrm{f}=22)$ olduğu görülmektedir. Bunu sırasıyla “morpakampus ( $f=13)$, eba $(f=8)$, okulistik $(f=7)$, sorubak $(f=2)$, leventyagmuroglu $(f=2)$, dersteknik $(f=1)$, sinifogretmeniyiz $(f=1)$, dersimiz $(f=1)$ ” web sitelerinin takip ettiği görülmektedir.

Eğitim Bilişim Ağı, Yenilik ve Eğitim Teknolojileri Genel Müdürlüğü tarafından hazırlanan "eba.gov.tr" çevrimiçi bir sosyal eğitim platformudur. Devlet destekli bu platformun diğer iki web sitesine oranla öğretmenler tarafindan daha az tercih edilmesi dikkat çekici bir bulgu olarak yorumlanabilir.

\section{Üçüncü Alt Probleme İlişkin Bulgular}

Araştırmanın üçüncü alt problemi, sınıf öğretmenlerinin, derslerde internet kullanımına ilişkin olumlu görüşlerini belirlemektir. Sınıf öğretmenlerinin derslerde internet kullanımı hakkındaki olumlu görüşleri 8 görüşte kodlanmış ve bu kodlara ilişkin frekans ve yüzdelere Tablo 4’te yer verilmiştir: 
Tablo 4. Sınıf Öğretmenlerinin Derslerde İnternet Kullanımına İlişkin Olumlu Görüşleri

\begin{tabular}{lll}
\hline İnternet Kullanımına İlişkin Olumlu Görüssler & f & $\mathbf{\%}$ \\
\hline Bilginin kalıcıllğını sağlama & 19 & 65,5 \\
Öğrencilerin dikkatlerini arttırma & 15 & 51,7 \\
Öğrencilerin derse ilgilerini arttırma & 10 & 34,4 \\
Daha fazla bilgi kaynağına erişimi sağlama & 3 & 10,3 \\
Akademik başarıyı arttırma & 2 & 6,8 \\
Öğrencilerin motivasyonlarını arttırma & 1 & 3,4 \\
Derste farklı öğretim yöntemlerinin kullanılmasını sağlama & 1 & 3,4 \\
Öğrencilerin, öğrenme sürecine aktif katılımını sağlama & 1 & 3,4 \\
\hline
\end{tabular}

Tablo 4'te görüldüğü gibi, sınıf öğretmenlerinin derste internet kullanımına ilişkin ifade ettiği en olumlu görüş, internet kullanımının bilgide kalıcılığg sağladığı yönündedir. Derslerde internet kullanıldığında, öğrencilerin dikkatlerinin arttığ 1 , derse ilgilerinin arttığı, daha fazla bilgi kaynağına kolayca erişim gerçekleştirebildikleri, akademik başarıyı arttırdığı, motivasyonlarını arttırdığı, derste öğretmenin farklı öğretim yöntemlerini kullanabilmesini sağladığı ve öğrencilerin öğrenme sürecine aktif katılımını sağladığı ifade edilen diğer olumlu görüşlerdir. Öğretim süreçlerinde internet kullanımının öğrencilerin derse olan ilgisini ve bilgileri kalıcı hâle getirmesini vurgulayan k2 bu görüşünü şöyle ifade etmiştir: "Derste internet kullanımı, derse ilgiyi arttırmaktadır. Öğrenci kazanımlarının çabuk kavranmasına, görsel zekâya sahip ögrencilerin bilgiyi kalıcı hâle getirmesine katkısı var.” Ayrıca internetin, işlenen konu ile ilgili somutlaştırıcı materyaller sağladığını ve bu yönüyle de öğrencilerin bilgileri daha kalıcı biçimde öğrendiğini ifade eden k7; “Konular somutlaştı̆̆ı için öğrencilerin dikkatlerini çekiyor. Farklı sitelerden hazlrlanan sorular, görseller, örnek olaylar konuları somutlaştırıyor. Konuların görsellerle desteklenmesi zihinde kalıcılı̆̆ sağllyor.” yorumunu yapmıştır. k19 kodlu katılımcı ise: “Dikkat çekici, tamamlayıcı, yeni bir bakış açısı olduğu için öğrenciler, internet kullanımı ile öğrenme sürecine aktif olarak katılıyorlar." diyerek internet kullanımı sayesinde öğrencilerin derslerde daha aktif olarak yer aldığını ifade etmiştir.

Öğretmenlerin görüşleri incelendiğinde derste internet kullanımının öğrencilerin motivasyonlarını arttırdığını, ilgilerini canlı tutmayı sağladığını ve dersi daha ilgi çekici kıldığını düşündükleri görülmektedir. Dolayısıyla bilginin de kalıcılığını sağladığı yönünde görüş bildirmişlerdir.

\section{Dördüncü Alt Probleme İlişkin Bulgular}


Araştırmanın dördüncü alt problemi, sınıf öğretmenlerinin, derslerde internet kullanımına ilişkin olumsuz görüşlerini belirlemektir. Sınıf öğretmenlerinin derslerde internet kullanımı hakkındaki olumsuz görüşleri 8 görüşte kodlanmış ve bu kodlara ilişkin frekans ve yüzdelere Tablo 5'te yer verilmiştir:

Tablo 5. Sınıf Öğretmenlerinin Derslerde İnternet Kullanımına İlişkin Olumsuz Görüşleri

\begin{tabular}{lll}
\hline İnternet Kullanımına İlişkin Olumsuz Görüşler & f & \% \\
\hline Herhangi bir olumsuz etki yok & 10 & 34,4 \\
Kullanım süresinin uzun olması & 7 & 24,1 \\
Vakit kaybettirme/ Dersten uzaklaştırma & 3 & 10,3 \\
Dikkat dağıtıcı olması & 2 & 6,8 \\
Çocuklara kötü örnek olabilecek içeriklere sahip olması & 2 & 6,8 \\
Aktif öğrenmeye engel oluşturması & 2 & 6,8 \\
Göz sağlığını olumsuz etkilemesi & 1 & 3,4 \\
Çocukları hazıra alıştırması & 1 & 3,4 \\
\hline
\end{tabular}

Tablo 5'te görüldüğü gibi, çalışmaya katılan sınıf öğretmenlerinin büyük çoğunluğu ( $\mathrm{f}=10)$ derste internet kullanımının herhangi bir olumsuz etkisi olmadığ yönünde görüş bildirmiştir. Bunun yanı sıra katılımcıların bir kısmı ( $\mathrm{f}=7$ ) internet kullanım süresinin uzun olması durumunda birtakım olumsuz sonuçların doğabileceği üzerinde durmaktadırlar. Öğrenciye vakit kaybettirme, dersten uzaklaştırma ( $f=3$ ), dikkat dağıtıcı olma ( $f=2)$, çocuklara kötü örnek oluşturabilecek içeriklerin olması $(f=2)$, aktif öğrenmeye engel oluşturma ( $\mathrm{f}=2$ ), göz sağlığını olumsuz etkileme ( $\mathrm{f}=1$ ) ve çocukları hazıra alıştırma ( $\mathrm{f}=1)$; öğretmenler tarafindan ifade edilen olumsuz görüşlerdir. k2 kodlu sınıf öğretmeni “Dikkat dağıtıcı bazı şeylerle (reklam gibi) karşılaşıldığında olumsuz etkisi olmaktadır.” görüşü ile, internetin derslerde kullanılırken birtakım dikkat dağıtıcı yönlerinin de bulunabileceğini ifade etmiş ve konu ile ilgisi olmayan reklamların çıkmasını bu düşüncesine örnek göstermiştir. İnterneti ders sürecinde kullanırken fazla hareketli olan görsellerin de amacını aşan şekilde olumsuz bir etkiye sahip olabileceğini düşünen k15 kodlu öğretmen: “Görsellik fazla hareketli olduğundan anlatım derslerinde katılım azalıyor.” diyerek bu görüşünü ifade etmiştir. Sınıf öğretmenlerinin arasında, öğrencilerin internet kullanarak işledikleri bazı derslerde dersi ciddiye almadıklarından yakınmaktadırlar. Bu düşünceyi k21 kodlu öğretmen "Bazen internet kullanımı onları dersten uzaklaştırlyor hissi veriyor. Ders gibi saymıyorlar, eğlenceye dönüştürüyorlar." şeklinde, k23 kodlu öğretmen ise; “Çoğu zaman oyun gibi düşünüp dersi yeterince dikkate almıyorlar.” şeklinde ifade etmiştir. 
Elde edilen bulgular incelendiğinde, öğretmenlerin çoğunluğunun derste internet kullanımı ile ilgili olarak hiçbir olumsuzluk dile getirmemiş oldukları dikkat çekmektedir. Ancak öğretmenlerin bir kısmı internet kullanımının süresinin uzaması durumunda birtakım problemlerin de beraberinde geldiğini düşündükleri dikkat çekmektedir. Uzun süreli internet kullanımın, öğrencilerin dikkatlerini ve ilgilerini dağıttığını, bu durumun da onlara vakit kaybettirdiğini düşünmektedirler. Günümüzde artan internet kullanımı ile birlikte öğretmenlerin, velilerin ve hatta kamuoyunun dikkatini çeken önemli noktalardan biri çocukların internetteki şiddet, korku veya cinsellik içeren kötü içeriklere maruz kalmasıdır. Çalışma bulguları da sınıf öğretmenlerinin bu benzer kaygıları taşıdığı yönündedir. Bu durumda, internette çocuk güvenliği için kullanılan güvenlik yazılım programlarının okullarda kullanımı ve yaygınlaştırılması tartışılabilir görünmektedir.

\section{Beşinci Alt Probleme İlişkin Bulgular}

Araştırmanın beşinci alt problemi, sınıf öğretmenlerinin, internet kullanımına ilişkin olarak kendilerini nasıl değerlendirdiklerini belirlemektir. Sınıf öğretmenlerinin kendi internet kullanımları hakkındaki görüşleri 4 görüşte kodlanmış ve bu kodlara ilişkin frekans ve yüzdelere Tablo 6'da yer verilmiştir:

Tablo 6. Sınıf Öğretmenlerinin Kendi İnternet Kullanımlarına İlişkin Görüşleri

\begin{tabular}{lll}
\hline Katılımcıların Kendi İnternet Kullanımlarına İlişkin Görüşleri & $\mathbf{f}$ & $\mathbf{\%}$ \\
\hline Orta düzeyde & 21 & 72,4 \\
Çok iyi düzeyde & 4 & 13,7 \\
İyi düzeyde & 3 & 10,3 \\
Zayıf düzeyde & 1 & 3,4 \\
\hline
\end{tabular}

Tablo 6' da görüldüğü gibi katılımcıların büyük çoğunluğu ( $\mathrm{f}=21)$ orta düzeyde bir internet kullanıcısı olduğunu ifade etmişlerdir. Bunun yanı sıra bazı katılımcılar çok iyi düzeyde ( $\mathrm{f}=4)$, bazıları iyi düzeyde $(\mathrm{f}=3)$ ve bir katılımc1 da zayıf düzeyde bir internet kullanıcısı olduğunu ifade etmiştir. Aynı zamanda katılımcılar, internet kullanımın mesleki gelişimlerine katkı sağladığını, hayatlarını kolaylaştırdığını, daha çok bilgiye kolaylıkla ulaşmayı sağladığını, derslerde kullanılacak her türlü materyal açısından zenginlik sağladığını ifade etmişlerdir. k1 kodlu sınıf öğretmeni, internet aracılığıyla eğitim ile ilgili gelişmeleri takip edebildiklerini "Kendime yetecek kadar kullanabiliyorum. Bu sayede ĕgitim ve öğretimdeki gelişmeleri daha hızlı takip edebiliyorum.” sözleriyle dile getirmiştir. Öğretmenler, internet kullanımının mesleki gelişimlerini desteklediğini “Interneti aktif bir şekilde kullanıyorum. Bilgiye hızlı ve kolay ulaşıldiğı için mesleki gelişsimime olumlu katkısı var. Meslektaşlarımla bilgi alışverişinde 
bulunma açısından çok yararlı.-k2” ve “Bilgi elimin altında, her daim bilmediğim konularda eksiklerimi tamamlıyorum. Eksiklerin kısa sürede giderilmesi güzel.-k16” sözleriyle ifade etmişlerdir. Sınıf öğretmenlerinin çoğunluğu kendilerini orta düzeyde bir internet kullanıcısı olarak tanımlarken bazı öğretmenler ise kendilerini çok iyi düzeyde internet kullanıcısı olarak tanımlamışlardır. k4 kodlu öğretmen bu düşünceyi, "Çok iyi bir internet kullanıcısıyım. Bilgiye hızlıca ulaşma imkânı sunan internet, her anımda bana yardımcı oluyor. Bilmediğim birçok bilgiyi edinebiliyorum. Sınıf içerisinde de ders sitelerine girip görsellerle, anlatacă̆ım konuyu pekiştirmemi ve farklı anlatım tekniklerini keşfetmemi să̆llyor.” sözleriyle belirtmiştir.

Bu bulgular doğrultusunda çalışmaya katılan öğretmenlerin büyük çoğunluğunun kendilerini orta düzey bir internet kullanıcısı olarak tanımladıkları söylenebilir.

\section{Altıncı Alt Probleme İlişkin Bulgular}

Araştırmanın altıncı alt problemi, sınıf öğretmenlerinin, internet erişim olanaklarını nasıl değerlendirdiklerini belirlemektir. Sınıf öğretmenlerinin internet erişim olanakları hakkındaki görüşleri 7 görüşte kodlanmış ve bu kodlara ilişkin frekans ve yüzdelere Tablo 7'de yer verilmiştir:

Tablo 7. Sınıf Öğretmenlerinin İnternet Erişim Olanaklarına İlişkin Görüşleri

\begin{tabular}{lll}
\hline İnternet Erişim Olanaklarına İlişkin Görüşler & f & $\mathbf{\%}$ \\
\hline İnternet kesintileri/ Yetersiz çekim gücü & 10 & 34,4 \\
Bazı web sitelerinin engelli olması & 10 & 34,4 \\
Erişimin yavaş olması & 7 & 24,1 \\
Yeterli erişim & 6 & 20,6 \\
İnternet bağlantısının olmaması & 3 & 10,3 \\
Okulda maddi sebepli internet erişim güçlüğü & 3 & 10,3 \\
Bilgisayarların eski olması & 3 & 10,3 \\
\hline
\end{tabular}

Tablo 7'de görüldüğü gibi, sınıf öğretmenlerinin çoğunluğu (f=10) okullarındaki internet bağlantılarının kesintilerinden, çekim gücünün yetersiz oluşundan ve genellikle video paylaşım sitelerinin (youtube gibi) engelli oluşundan söz etmişlerdir. Erişimin yavaş olması $(f=7)$ da olumsuz olarak ifade edilen bir diğer görüştür. Bunun yanı sıra öğretmenlerin bazıları ise $(\mathrm{f}=6)$ okuldaki internet erişim olanaklarının yeterli düzeyde olduğunu ifade etmişlerdir. Olumsuz olarak ifade edilen diğer görüşler; internet bağlantısının olmaması $(\mathrm{f}=3)$, okulda internetin paralı olması $(\mathrm{f}=3)$ ve bilgisayarların eski olması ( $\mathrm{f}=3$ ) şeklindedir. Bulgular incelendiğinde, sınıf öğretmenlerinin internet erişim olanaklarına ilişkin en çok vurguladıkları noktanın internet kesintileri ve yetersiz çekim gücü olduğu görülmektedir. Örneğin k6 kodlu öğretmen "Yeterli internet çekim gücü 
olmaması sorununu yaşlyoruz" diyerek bu durumu ifade etmiştir. Bazı web sitelerinin okullarda engelli olması da sınıf öğretmenlerinin değerlendirdiği diğer bir önemli nokta olarak görülmektedir. k9 kodlu sınıf öğretmeni "Engelli sitelerin çok yoğun olması. Faydal olabilecek sitelerin de engellenmesi olumsuz. Bilgisayarlartn eski olmast, internetin yeteri kadar güçlü olmaması. " sözleriyle okulunun internet erişim olanaklarını değerlendirmiştir. k15 kodlu öğretmen ise hem okuldaki internet kesintilerinden hem de yararlandığ web sitelerinin engelli oluşu nedeniyle yaşadığı sıkıntıyı "İnternet ağındaki kesintiler, video sitelerinin engelli oluşu benim verimimi düşürüyor.” sözleriyle ifade etmiştir. Okuldaki bilgisayarların eski olması da öğretmenlerin internet erişiminde karşılaştıkları diğer bir problem alanı olarak dikkat çekmektedir. k23 kodlu öğretmen "Çoğu zaman sinffta internet kullanıminda sorun yaşlyoruz. İnternet var ama bilgisayarda açıp kullanamıyorum. Çünkü bilgisayar çok eski ve kullanışsız." diyerek bu görüşünü dile getirmiştir.

Bulgular incelendiğinde, öğretmenlerin okullarda internete erişim olanakları ile ilgili olarak ciddi sıkıntılar yaşadıkları ifade edilebilir. Bu olumsuzlukların, öğretmenlerin derste interneti kullanım sıklığını ve kalitesini olumsuz etkileyeceği düşünülebilir.

\section{Yedinci Alt Probleme İliş̧kin Bulgular}

Araştırmanın yedinci alt problemi sınıf öğretmenlerinin, okullarında internet kullanım imkânları bakımından okullarından beklentilerini belirlemektir. Bu kapsamda öğretmenlerin görüşleri 9 kategoride kodlanmış ve bu kodlara ilişkin frekans ve yüzdelere Tablo 8'de yer verilmiştir:

Tablo 8. Sınıf Öğretmenlerinin Okullarındaki İnternet Kullanım İmkânlarına İlişkin Beklentileri

\begin{tabular}{lll}
\hline Sınıf Öğretmenlerinin İnternet İmkânlarına İlişkin Beklentileri & f & $\mathbf{\%}$ \\
\hline Video izleme sitelerine erişim & 9 & 31 \\
Hızlı internet bağlantısı & 8 & 27,5 \\
Bilgisayarların yenilenmesi & 4 & 13,7 \\
Hiçbir beklentinin bulunmaması & 3 & 10,3 \\
Kesintisiz internet bağlantısı & 2 & 6,8 \\
Eğitim içerikli yeni web sitelerinin kurulması & 2 & 6,8 \\
Akıllı tahta uygulaması & 2 & 6,8 \\
Her sinıfta internet bağlantısının olması & 1 & 3,4 \\
İnternete ücretsiz erişim & 1 & 3,4 \\
\hline
\end{tabular}

Tablo 8'de görüldüğü gibi sınıf öğretmenlerinin en yoğun düzeyde beklentileri $(\mathrm{f}=9)$, Youtube gibi video izleme web sitelerine erişimin sağlanmasıdır. Bu tarz sitelerin okullarda engelli olduğu ifade edilmiş̧ir. Okullardaki internet bağlantısının daha hızlı 
olması ( $f=8)$ bir diğer önemli beklentidir. Sınıf öğretmenlerinin bir kısmı ise ( $f=4)$ okullardaki bilgisayarların eski olduğunu ve bu bilgisayarların yenilenmesinin gerekli olduğunu ifade etmişlerdir. Diğer beklentiler; internet bağlantısının kesintisiz olması $(\mathrm{f}=2)$, eğitim içerikli yeni web sitelerinin kurulması $(\mathrm{f}=2)$, sınıflara akıllı tahta uygulamalarının getirilmesi ( $f=2)$, her sınıfta internet bağlantısının olması $(f=1)$ ve internete erişimin ücretsiz olması $(\mathrm{f}=1)$ olarak sıralanmıştır. Bunun yanı sıra okullarındaki internet kullanım imkânlarını yeterli olarak değerlendiren ve hiçbir yenilik beklentisi bulunmayan katılımcıların $(f=3)$ da olduğu dikkat çekmektedir. Sınıf öğretmenlerinin okullardaki internet erişim olanakları ile ilgili olarak yaşadıkları olumsuz durumların giderilmesine yönelik görüşler bildirdikleri görülmektedir. Okullarda erişimi engelli olan video izleme siteleri gibi web sitelerinin erişime açılması beklentisi yoğun bir şekilde ifade edilmiştir. Örneğin k11 kodlu öğretmen “Youtube erişiminin sağlanması" ifadesiyle bu görüşü dile getirmiştir. Sınıf öğretmenleri eğitim-öğretim süreçlerinde kullanmak üzere eğitim içerikli web sitelerinin de hem sayıca hem de içerik niteliği bakımından geliştirilme ihtiyacı içinde olduklarından söz etmişlerdir. Örneğin k22 kodlu sınıf öğretmeni: “EBA'nın MORPA gibi, hatta daha güncel ve güzel hazırlanıp ders anlatımlarında ögrencilere çeşitlilik să̆lanmal, animasyon ve sunumları olmall." şeklinde bu görüşü dile getirmiştir. Akıllı tahta uygulamalarının tüm okullarda olması beklentisini ifade eden k20 kodlu sınıf öğretmeni "Okulumuza bir an önce akıllı tahtaların kurularak internet hızının artırılması" sözlerine yer vermiştir.

Elde edilen bulgular 1şığında öğretmenlerin öncelikli olarak video izleme sitelerine erişimin kısıtlı olmasından rahatsız oldukları ve bu konuda çözüm beklentisi içinde oldukları ifade edilebilir. Video izleme sitelerinde derslerle ilişkilendirilebilecek pek çok farklı içerikte video bulunması öğretmenlerin bu eleştirisini açıklar niteliktedir. İnternetin etkili kullanılabilmesi için gerekli olan internet erişim hızı, bilgisayarların özellikleri, internet bağlantısının kesintisiz olması gibi özellikler de öğretmenler tarafından ifade edilen diğer beklentilerdir.

\section{Tartışma, Sonuç ve Öneriler}

Sınıf öğretmenlerinin eğitim sürecinde internet kullanım durumlarının betimlendiği bu çalışmada sınıf öğretmenlerinin interneti; sırasıyla; dersi planlama, bankacılık, e-posta işlemleri, sosyal paylaşım sitelerinin kullanımı, alışveriş, güncel haberleri takip etme ve ders işleme amacıyla kullandıkları sonucuna ulaşılmıştır. İlgili 
alanyazın incelendiğinde öğretmenlerin ve öğretmen adaylarının internet kullanım amaçlarının; iletişim kurma (Akkoyunlu, 2002; Demirci Güler, Kaya ve Uzun, 2014; NCES, 2000; Okay, 2010), e-posta gönderme (Akkoyunlu, 2002; Deniz ve Coşkun, 2004; Okay, 2010), bilgiye ulaşma (Atav, Akkoyunlu ve Sağlam, 2006; Demirci Güler, Kaya ve Uzun, 2014; Okay, 2010), haberleşme (Akkoyunlu ve Yılmaz, 2005; Atav, Akkoyunlu ve Sağlam, 2006), haber takibi yapma (Demirci Güler, Kaya ve Uzun, 2014), araştırma yapma (Demirci Güler, Kaya ve Uzun, 2014; Okay, 2010; Oral, 2004) ve sohbet etme (Okay, 2010) alanlarında yoğunlaştığı görülmektedir. Orhan ve Akkoyunlu (2004) tarafından ilköğretim öğrencileri ile yürütülen çalışma sonuçlarında ise öğrencilerin yaşlarının arttıkça interneti oyun amaçlı kullanımın azaldı̆̆ı ve çok amaçlı kullanımın arttığı vurgulanmıştır. Bu durumda yetişkinlerin yaşlarıyla da ilişkili bir biçimde interneti çok amaçlı olarak kullandıkları sonucuna ulaşılmaktadır.

Sınıf öğretmenleri ders hazırlıklarını yaparken yararlandıkları web sitelerini en çok kullanılandan başlayarak "egitimhane.com, morpakampus, eba, okulistik, sorubak, leventyagmuroglu, dersteknik, sinifogretmeniyiz, dersimiz” olarak sıralamışlardır. Araştırmanın bu sonucuna ilişkin ilgi çekici olan nokta, öğretmenlerin devlet destekli bir web sitesi olan $e b a$ 'yı ilk sırada tercih etmiyor olmalarıdır. Yenilik ve Eğitim Teknolojileri Genel Müdürlüğü tarafından öğretmen ve öğrencilerin kullanımına ücretsiz olarak sunulan çevrimiçi bir sosyal eğitim platformu olan Eğitim Bilişim Ağ̀ (EBA)'nda Talim Terbiye Kurulu tarafından onaylanan bütün ders içerikleri, öğrenme nesnesi ve ekitap formatında, e-içerik yönetim sistemi paylaşılmaktadır. EBA, FATİH Projesi kapsamında dağıtılan tablet bilgisayarlarda da yüklü olarak bulunmaktadır (EBA, 2018). Eğitim içerikli web sitelerinin öğrenciler ve öğretmenlere tanıtılmasına, farkındalığın arttırırlmasına ilişkin çalışmalar bulunsa da (Coşkunserçe ve İşçitürk, 2019), daha fazla çalışmaya ihtiyaç olduğu sonucuna ulaşılmıştır.

Sınıf öğretmenlerinin görüşleri doğrultusunda derslerde internet kullanıldığında, öğrencilerin dikkatlerinin arttığ erişim sağladıkları, öğrencilerin akademik başarılarını ve motivasyonlarını arttırdığı, derste öğretmenin farklı öğretim yöntemlerini kullanabilmesini ve öğrencilerin öğrenme sürecine aktif katılımını sağladığı sonucuna ulaşılmıştır. Öğretim sürecinde interneti kullanmanın, sürece olumlu katkıları olduğu görüşü farklı çalışma sonuçları ile de 
desteklenmektedir (Akkoyunlu, 2002; Çağıltay, Çakıroğlu, Çağıltay ve Çakıroğlu, 2001; Demirci Güler, Kaya ve Uzun, 2014).

Araştırmaya katılan sınıf öğretmenleri, derslerde interneti kullanma konusunda birtakım endişeler de taşımaktadır. İnternet kullanım süresinin uzun olması durumunda birtakım olumsuz sonuçların doğabileceği vurgulanmıştır. İnternet kullanımının öğrenciye vakit kaybettirme, dersten uzaklaştırma, dikkat dağıtıcı olma, internette çocuklara kötü örnek oluşturabilecek içeriklerin olması, aktif öğrenmeye engel oluşturma, göz sağlığını olumsuz etkileme ve çocukları hazıra alıştırma gibi olumsuz birtakım etkiler olabileceği kaygısı dikkat çekmektedir. Çocukların bilgisayar ve internet kullanımından kaynaklı olarak derslere ilgisizlik problemleri yaşadığı bilinmektedir (Çoklar, Güven ve Işık, 2016). Benzer şekilde teknolojik araçların öğrencinin öğrenme yaşantısını olumsuz etkilediği ortaya koyan çalışmalar da bulunmaktadır (Erbil ve Kocabaş, 2019). Günümüzde teknolojinin hayatımızın her alanına girmesi ile birlikte en güncel tartışmalardan biri de teknolojinin olası olumsuz sonuçlarıdır. Pek çok farklı platformda çocukların teknoloji ile erken yaşta tanışmasının olumlu-olumsuz etkileri, internet ve internet bağımlılığ 1 gibi konular tartışılmakta ve bilim çevrelerinin teknoloji kullanımına temkinli yaklaştıkları görülmektedir. Nitekim internet kullanımının artan yalnızlık ve depresyon ile (Rajani ve Chandio, 2004), akademik başarıda düşüş ile (Bayraktar ve Gün, 2007) ve aile içi iletişimin zayıflaması ile (Çoklar, Güven ve Işık, 2016; Rajani ve Chandio, 2004; Sook-Jung ve Young-Gil, 2007) ilişkili olduğu sonuçlarına ulaşılmıştır. Fen Bilimleri öğretmenleri ile yapılan çalışma sonucunda da (Demirci Güler, Kaya ve Uzun, 2014) öğretmenlerin internet kullanımı ile ilgili olarak benzer kaygılar taşıdıkları görülmektedir. Öğrencilerin dikkatlerini dağıtması ve öğrenciler için zarar verici görüntüler barındırma, internet kullanımına dair sorunlar olarak sıralanmıştır. İnternetin öğrenciler için hazır bilgi sunuyor olması ve öğrencileri araştırma becerilerinden uzaklaştırması gibi birtakım endişeler de ifade edilmektedir (Açıkalın, 2009).

Araştırmaya katılan sınıf öğretmenlerinin çoğunluğu kendilerini orta düzeyde bir internet kullanıcısı olarak tanımlamışlardır. Sınıf öğretmenleri internet kullanımın mesleki gelişimlerine katkı sağladığını, hayatlarını kolaylaştırdığını, daha çok bilgiye kolaylıkla ulaşmayı sağladığını, derslerde kullanılacak her türlü materyal açısından zenginlik sağladığını ifade etmişlerdir. Akkoyunlu (2002), özellikle sınıf ve branş 
öğretmenlerinin internet kullanımı konusunda bilişsel alt yapılarında yetersizlikler olduğu ve bu sebeple de öğretim sürecinde internet kullanımının engellendiğini ifade etmiştir. Öğretmenlerin internet kullanımlarının düşük ve orta düzeyde yoğunlaşmasının pek çok farklı sebebi olabilir. Akpınar (2003), öğretmenlerin bilgi teknolojilerini kullanımında yükseköğretimin etkisini araştırmıştır. Akpınar (2003)'ın çalışma sonucunda metropol veya sahil kentlerinden birinde yükseköğretimini tamamlayan öğretmenlerin doğu, güneydoğu ve iç yörelerde öğrenimini tamamlayan öğretmenlere oranla internet kaynaklarını sınıf içi ve dışı ders etkinliklerinde anlamlı düzeyde daha fazla kullandıkları sonucuna ulaşmıştır. Öğretmenlerin lisansüstü eğitim yapmak gibi öğrenim düzeyleri arttıkça eğitsel internet kullanımı öz-yeterlik inançlarının da yükseldiği bilinmektedir (Baş, 2011; Tuncer ve Özüt, 2012). Literatürde eğitsel internet kullanım becerileri arttıkça bilgi edinme becerilerinin de arttığı sonuçlarına rastlanmıştır (Kaya, Balay ve Adıgüzel, 2014). Kısaca özetlemek gerekirse öğretmenlerin internet kullanma düzeylerinin artmasının; kendilerini meslekî alanda geliştirmeleri ve buna bağlı olarak bilişim teknolojilerini kullanmaya ilişkin öz-yeterlik inançlarının artması ile mümkün olabileceği sonucuna ulaşılmıştır.

Sınıf öğretmenlerinin çoğunluğu okullarındaki internet bağlantılarının kesilmesini, çekim gücünün yetersiz oluşunu, erişimin yavaş oluşunu, internet bağlantısının olmayışını, okulda internetin paralı olmasını ve bilgisayarların eski olmasını ve genellikle video paylaşım sitelerinin (youtube gibi) engelli oluşunu olumsuz olarak değerlendirmişlerdir. Bunun yanı sıra öğretmenlerin bazıları ise okuldaki internet erişim olanaklarının yeterli düzeyde olduğunu ifade etmişlerdir. Akkoyunlu (2002) tarafından yürütülen çalışmada benzer şekilde okullarda internet kullanımına ilişkin birtakım fiziki alt yapı eksikleri vurgulanmaktadır. Her ne kadar 2000'li yılların başlarındaki okul teknolojik alt yapı imkânları ile günümüzdeki okulların teknolojik imkânları arasında farklar olsa da okullarımızda hâlâ internet erişimi, hızı ve bilgisayar olanakları bağlamında birtakım eksiklerin bulunduğu sonucu dikkat çekmektedir. Bu durumun, okulların teknolojik alt yapısını güçlendirmeye yönelik bir proje olan FATİH projesinin henüz ilkokullarda uygulanmaya başlamamasından kaynaklı olabileceği düşünülmektedir (TEDMEM, 2016).

Sınıf öğretmenlerinin okullarında olmasını istedikleri yenilikler; Youtube gibi video izleme web sitelerine erişimin sağlanması, internet bağlantısının daha hızlı olması, 
bilgisayarların yenilenmesi, internet bağlantısının kesintisiz olması, eğitim içerikli yeni web sitelerinin kurulması, sınıflara akıllı tahta uygulamalarının getirilmesi, her sınıfta internet bağlantısının olması ve internete erişimin ücretsiz olması olarak sıralanmıştır. Bunun yanı sıra okullarındaki internet kullanım imkânlarını yeterli olarak değerlendiren ve hiçbir yenilik beklentisi bulunmayan katılımcıların da olduğu sonucuna ulaşılmıştır. Günümüzde teknolojik cihazların hayatın her alanındaki kullanımının artmasıyla, eğitim ortamlarında da ihtiyaçlar ve beklentiler bu doğrultuda şekillenmektedir. Dolayısıyla sınıf öğretmenlerinin okul ortamlarında bilgisayar, projeksiyon, akıllı tahta gibi cihazların kullanıma hazır şekilde bulunmasını bekledikleri sonucuna ulaşıımıştır. Yapılan çalışmalar eğitim ortamlarında ulaşılamayan bu tarz teknolojik araçların, bu araçlara erişemeyen öğrenciler açısından firsat eşitsizliği oluşturduğunu ortaya koymaktadır (Alkan, Düz, Orman, Çiçek, Koldanca ve Günday, 2011). Milli Eğitim Bakanlığı tarafından geliştirilen ve 2011 yılında uygulamaya başlanan FATİH projesi kapsamında okulların teknolojik alt yapısını güçlendirmeye yönelik çalışmalar yürütülmektedir. Bu bağlamda 2016 yılı sonu itibariyle 432.288 adet etkileşimli/akıllı tahtanın kurulumunun tamamlandığı ifade edilmektedir (TEDMEM, 2016). Hâlâ istenilen düzeyde tamamlanmamış olan bu projenin de teknolojik alt yapı ile ilgili öğretmenlerin beklentilerini karşılamaya yönelik sonuçlar taşıyabileceği düşünülmektedir.

Çalışmanın sonuçları doğrultusunda, sınıf öğretmenlerinin, okullarda internet kaynaklarına ulaşım koşullarının iyileştirilmesi, internet kaynaklarının etkili kullanımı ile ilgili farkındalık kazandırılması, online ders içerikleri barındıran web sitelerinin güncellenmesi, geliştirilmesi ve yaygınlaştırılması konusunda MEB koordinasyonunda çalışmalar yürütülmesi önerilmektedir.

\section{Makalenin Bilimdeki Konumu}

Temel Eğitim/ Sınıf Öğretmenliği/ Eğitim Programları ve Öğretim

\section{Makalenin Bilimdeki Özgünlüğü}

Literatürde sınıf öğretmenlerinin internet kullanımlarına ilişkin farklı çalışmalar olmakla birlikte farklı çalışma grubu ve farklı zamanlarda yapılan çalışmalarla, var olan 
durumdaki benzerlik ve farklılıkları ortaya koymaya ihtiyaç duyulmaktadır. Bu amaçla yapılan çalışmanın alana katkı getireceği düşünülmektedir.

\section{Kaynaklar}

Açıkalın, M. (2009). Pre-service elemantary teachers' beliefs about use of the internet in the social studies classroom. European Journal of Teacher Education, 32(3), 305320.

Akkoyunlu, B. (2002). Öğretmenlerin internet kullanımı ve bu konudaki öğretmen görüssleri. [Use of internet by teachers and their opinions on the issue], Hacettepe University Journal of Education, 22, 1-8.

Akkoyunlu, B. ve Yılmaz, M. (2005). Öğretmen adaylarının bilgi okuryazarlık düzeyleri ile internet kullanım sıklıkları ve internet kullanım amaçları [Prospective teachers' 1nformation literacy level, internet usage frequencies and purposes of their internet usage]. Eurasian Journal of Educational Research, 19, 1-14.

Akpınar, Y. (2003).Öğretmenlerin yeni bilgi teknolojileri kullanımında yükseköğretimin etkisi: İstanbul okulları örneği [The impact of higher education on teachers' use of new information technologies: İstanbul schools example]. Turkish Online Journal of Educational Technology, 2(2), 79-96.

Alkan, T., Düz, A., Orman, R., Çiçek, H., Koldanca, İ. ve Günday, Ö. (2011). Eğitimde FATİH (Fırsatları artırma teknolojiyi iyileştirme hareketı) Projesi: Türk eğitimöğretim sisteminde teknoloji odaklı değişim süreci. 11th International Educational Tecnology Conference, 2, 1471-1474.

Atav, E.; Akkoyunlu, B. ve Sağlam, N. (2006). Öğretmen adaylarının internete erişim olanakları ve kullanım amaçları [Prospective teachers' internet access facilities and their internet usage]. Hacettepe University Journal of Education, 30(2006), 37-44.

Baş, G. (2011). İlköğretim öğretmenlerinin eğitsel internet kullanımı öz-yeterlik inançlarının farklı değişkenler açısından incelenmesi [Examination of educational internet use self-efficacy beliefs of elementary school teachers in terms of different variables]. Educational Technology Theory and Practice, 1(2), 35-51.

Bayraktar, F. ve Gün, Z. (2007). Incidence and correlates of internet usage among adolescents in north cyprus. Cyberpsychology \& Behavior, 10(2), 191-197. 
Becker, H.J. (1999). Internet use by teachers: conditions of professional use and teacherdirected student use. http://www.crito.uci.edu/TLC/findings/Internet-Use/startpage.htm

Borich, G. D. (2014). Etkili öğretim yöntemleri [Effective teaching methods]. (Ed. M. Bahaddin Acat). Ankara: Nobel Publishing.

Coşkunserçe, O. ve İşçitürk, G. B. (2019). Eğitim bilişim ağı (EBA) platformu hakkinda öğrencilerin farkindaliğinin artirilmasina yönelik bir durum çalişmasi. Eğitimde Nitel Araştırmalar Dergisi - Journal of Qualitative Research Education, 7(1), 260276. DOI: 10.14689/issn.2148-2624.1.7c1s.12m

Creswell, J. W. (2013). Educational research: planning, conducting and evaluating quantitative and qualitative research. Fourth Edition, USA: Pearson.

Çağıltay, K., Çakıroğlu, J., Çağıltay, N. ve Çakıroğlu, E. (2001). Öğretimde bilgisayar kullanımına ilişkin öğretmen görüşleri [Teachers' perspectives about the use of computers in education]. Hacettepe University Journal of Education, 21, 19-28.

Çoklar, A. N., Güven, C. ve Işık, O. (2016). Sosyal bilgiler öğretmenlerinin internet kullanımı konusunda rehberlik durumları. 4. Uluslararası Öğretim Teknolojileri ve Öğretmen Eğitimi Sempozyumu (ITTES 2016), 6-8 Ekim 2016, Elazığg, 231-243.

Demirci Güler, M. P.; Kaya, S. ve Uzun, A. (2014). Fen bilimleri öğretmenlerinin öğretimde internet kullanımına ilişkin görüşleri (Kırşehir ili örneği) [Science teachers' views on the internet use in education (the case of Kırşehir)]. Ahi Evran University Kırşehir Journal of Education, 15(1), 263-280.

Deniz, L. ve Coşkun, Y. (2004). Öğretmen adaylarının internet kullanımına yönelik yaşantılar [Internet experiences of prospective teachers]. M.Ü. Atatürk Journal of Educational Sciences, 20, 39-52.

EBA. (2018). 12.02.2019 tarihinde http://www.eba.gov.tr/hakkimizda adresinden alınmıştır.

Erbil, D. G. ve Kocabaş, A. (2019). Sınıf öğretmenlerinin eğitimde teknoloji kullanımı, tersine çevrilmiş sınıf ve işbirlikli öğrenme hakkındaki görüşleri. Illköğretim Online, 18(1), 31-51.

Erdur-Baker, Ö. \& Kavşut, F. (2007). Akran zorbalığının yeni yüzü: Siber Zorbalık. Eurasian Journal of Educational Reserach, 27, 31-42. 
Gentile, D. (2009). Pathological video-game use among youth ages 8 to 18: A national study. Psychological Science, 20(5), 594-602.

Glesne, C. (2012). Nitel araştırmaya giriş [Introduction to qualitative research]. (Ed.: Ali Ersoy ve Pelin Yalçınoğlu). Ankara: Anı Publishing.

Kaptan, S. (1973). Eğitim ve sosyal bilimler bilimsel araştırma teknikleri [Education and social sciences scientific research techniques]. Ankara: Rehber Publishing.

Kaşıkçı, D. N., Çağıltay, K., Karakuş, T., Kurşun, E. ve Ogan, C. (2014). Türkiye ve avrupa' daki çocukların internet alışkanlıkları ve güvenli internet kullanımı. Eğitim ve Bilim, 39(171), 230-243.

Kaya, A.; Balay, R. ve Adıgüzel, A. (2014). Öğretmen adaylarının eğitsel internet kullanma becerileri ile bilgi edinme becerileri arasındaki ilişki düzeyi [The relationship between teacher candidates' educational internet-use skills and their knowledge acquisition skills]. Journal of Educational Sciences Research, 4(1), 8399.

Kimmons, R.; Clark, B. \& Lim, M. (2017). Understanding web activitiy patterns among teachers, students and teacher candidates. Journal of Computer Assisted Learning, 33(6), 588-596.

MEB. (2018). Eğitimde Fatih Projesi. 12.02.2019 tarihinde http://fatihprojesi.meb.gov.tr/proje-hakkinda adresinden alınmıştır.

Merriam, S. B. (2013). Nitel araştırma: desen ve uygulama için bir rehber [Qualitative research: A guide for pattern and application]. (Ed.: Selahattin Turan). Ankara: Nobel Publishing.

Miles, M, B., ve Huberman, A. M. (1994). Qualitative data analysis: An expanded Sourcebook. (2nd ed). Thousand Oaks, CA: Sage

NCES. [National Center for Education Statistics]. (2000). Teacher use of computers and the internet in public schools. U.S Department of Education Office of Educational Research and Improvement.

Okay, Ş. (2010). Teknik öğretmen adaylarının internet kullanım amaçlarının incelenmesine ilişkin bir araştırma [A research on investigation of internet using purposes of technical teacher candidates]. Electronic Journal of Machine Technologies, 7(1), 97-109. 
Oral, B. (2004). Öğretmen adaylarının internet kullanma durumları [The internet usage of teachers candidates]. XIII. National Educational Sciences Workshop. 6-9 July 2004. İnönü University Faculty of Education, Malatya.

Orhan, F. ve Akkoyunlu, B. (2004). İlköğretim öğrencilerinin internet kullanımları üzerine bir çalışma [A study on the use of internet by primary school students]. Hacettepe University Journal of Education. 26(2004), 107-116.

ÖYEGM [Öğretmen Yetiştirme ve Eğitimi Genel Müdürlüğü]. (2008). Sinıf ögrretmeni alan yeterlikleri [Classroom teacher qualifications]. Ankara.

Rajani, M.K. ve Chandio; M. S. (2004). Use of internet and its effects on our society. national conference on emerging technologies. http://szabist.pk/Publications/Session\%20VIII\%20Paper\%20No\%202\%20(P\%201 57-161).pdf

Schunk, D. H. (2014). Öğrenme teorileri [Learning theories]. (Ed. Muzaffer Şahin). Ankara:Nobel Publishing.

Sook-Jung, L. ve Young-Gil, C. (2007). Children's internet use in a family context: influence on family relationships and parental mediation. Cyberpsychology \& Behavior. 10(5), 640-644.

Sönmez, V. ve Alacapınar, F. G. (2011). Örneklendirilmiş bilimsel araştırma yöntemleri [Sampled scientific research methods]. Ankara: Anı Publishing.

Şahan, H. H. (2011). Internet tabanlı ögrenme [Internet based learning]. (Ed: Özcan Demirel). Eğitimde Yeni Yönelimler [New Trends in Education] in 239-249. Ankara: Pegem Academy.

TEDMEM. (2016). 2016 Ĕgitim Değerlendirme Raporu. Ankara: Türk Eğitim Derneği Yayınları.

Tuncer, M. ve Özüt, A. (2012). Sınıf öğretmeni adaylarının eğitsel internet kullanımına yönelik öz yeterlik inançları [Self-efficacy perception of preservice class teachers to educational internet usage]. International Periodical for The Languages, Literature and History of Turkish or Turkic, 7(2), 1079-1091.

Wu, A. M., Chen, J. H., Tong, K. K., Yu, S., \& Lau, J. T. (2018). Prevalence and associated factors of Internet gaming disorder among community dwelling adults in Macao, China. Journal of Behavioral Addictions, 7(1), 62-69. 
Yıldırım, A. ve Şimşek, H. (2008). Sosyal bilimlerde nitel araştırma yöntemleri [Qualitative research method in the social sciences]. Ankara: Seckin Publishing.

URL 1: (http://www.tuik.gov.tr/PreHaberBultenleri.do?id=24561).

\section{Summary}

\section{Statement of Problem}

In Turkey, "Generic Teacher Competencies" defined by the General Directorate of Teacher Training and Development within the Ministry of Education includes "arranging learning environments in an effective way" as one of the most important qualifications for a teacher. In this context, teachers are expected to be able to effectively use the internet which is the most commonly used technological resource and also to teach students how to use it. The widespread use of the Internet in learning environments has reshaped the interaction and the relationship between students and teachers. The rapid increase in Internet usage has facilitated information access. Therefore, the role of the teacher has turned from a concept that transfers information and knows everything into a structure that directs his/her students to information, and guides them in this regard (Akkoyunlu, 2002). Among the field competencies related to classroom teachers (OYEGM, 2008), there are many areas of competence related to "making use of information technology for professional development and communication" and ensuring that students use scientific and technological concepts correctly and effectively.

In Turkey, given that the Internet is the most widely used information technology in our schools, as well as being able to use the Internet effectively, it is seen that teachers are also expected to take the lead in the direction of teaching students the correct and efficient way to use it. The purpose of the research in this context is as follows:

\section{Purpose of the Research}

The purpose of this research is to demonstrate the use of internet by classroom teachers. For this purpose, sub-problems of the research are determined as follows:

1. What are the purposes of classroom teachers' internet use?

2. What are the websites where classroom teachers use to prepare their lessons?

3. What are the positive opinions of classroom teachers about using the internet in lessons? 
4. What are the positive opinions of classroom teachers about using the internet in lessons?

5. How do classroom teachers assess themselves in terms of internet use?

6. How are classroom teachers assessing their access opportunities to internet use?

7. What are the innovations that classroom teachers want in terms of internet use in their schools?

\section{Method}

This is a qualitative study in the survey model which aims to reveal the internet usage of the classroom teachers. The study is designed in the pattern of case study from qualitative research patterns.

The study group of the research consists of 29 classroom teachers working in Amasya Province in 2016-2017 academic year. In the study, semi-structured interview form was used as data collection tool to reveal the internet usage of the classroom teachers. There are 12 questions about the internet use of classroom teachers in the interview form, including the sub problems of the study. The opinions of the classroom teachers on the form were analyzed by descriptive analysis technique. Inter-coder reliability is calculated to ensure reliability in the analysis of qualitative data obtained from the interview form. With this calculation, the qualitative data is coded by more than one encoder and the reliability between the coders is calculated (Creswell, 2013). In order to increase the reliability of the study, care was taken while creating the report of collected data in detail and the opinions of the individuals participating in the study were directly cited (Yıldırım and Şimşek, 2008, p. 257).

\section{Findings}

\section{Findings Related to the First Subproblem}

The first sub-problem of the research is to determine the purpose of internet usage of classroom teachers. All participants in this survey stated that they use internet even if it's for different purposes. It is seen that the classroom teachers use the Internet mostly in order to prepare the lessons ( $f=28$ ), for banking operations ( $f=22$ ), e-mail operations ( $f=21$ ), using social sharing websites $(f=20)$, shopping ( $f=18)$, reading news $(f=1)$, and utilization in lesson $(\mathrm{f}=1)$.

\section{Findings Related to the Second Subproblem}


The classroom teachers were mostly benefited from "egitimhane.com" ( $f=22$ ) when they were preparing their lessons. Respectively, It is followed by "morpakampus $(f=13)$, eba $(f=8)$, okulistik $(f=7)$, sorubak $(f=2)$, leventyagmuroglu $(f=2)$, dersteknik $(\mathrm{f}=1)$, sinifogretmeniyiz $(\mathrm{f}=1)$, dersimiz $(\mathrm{f}=1)$ " websites.

\section{Findings Related to the Third Subproblem}

The third sub-problem of the research is to determine the positive opinions of the classroom teachers regarding the use of the internet in the lessons. The most positive opinion expressed by classroom teachers regarding the use of internet in the lesson is that the use of internet makes the information persistant.

\section{Findings Regarding the Fourth Subproblem}

The fourth subproblem of the research is to determine the negative opinions of the class teachers regarding the use of internet in the lessons. The majority ( $\mathrm{f}=10$ ) of the classroom teachers who participated in the study expressed the opinion that there was no negative effects of internet usage in lessons.

\section{Findings Regarding the Fifth Subproblem}

The fifth sub-problem of the research is to determine how classroom teachers evaluate themselves about internet usage. The vast majority of participants ( $f=21$ ) stated that they were medium level Internet users.

\section{Findings Regarding the Sixth Subproblem}

The sixth subproblem of the research is to determine how classroom teachers assess internet access opportunities. The majority of classroom teachers $(\mathrm{f}=10)$ mentioned that their internet links were inadequate, their wireless attraction power was inadequate, and that video sharing websites (such as YouTube) were generally blocked.

\section{Findings Regarding the Seventh Subproblem}

The seventh sub-problem of the research is to identify the innovations that the classroom teachers want the schools to have in terms of internet usage. Innovation that classroom teachers want to have the most is to provide access to video streaming websites like Youtube $(\mathrm{f}=9)$.

\section{Discussion and Conclusion}

In line with the opinions of the classroom teachers, the results has been reached that when the internet is used in the lessons: the students' attention increase, their interest 
in the lesson increase, more information resources become easier to access, the academic achievements and motivations of the students increase, teachers can use different teaching methods and students actively participate in the learning process. The opinion that the internet usage in education process amplifies this process is supported by different study results as well (Çağıltay, Çağıloğlu, Çağıltay and Çakıroğlu, 2001; Akkoyunlu, 2002, Demirci Güler, Kaya and Uzun, 2014).

The classroom teachers who participated in the research also have some concerns about using the internet in the lessons. It has been emphasized that if the internet usage time is long, some negative results may occur. It is noteworthy that the use of the Internet has the potential to have negative effects such as causing students' waste of time, reduced attendance to lesson, being distracting, having content that can be a bad example for children, obstructing active learning, negatively affecting eye health. With the advent of technology in all areas of our lives today, one of the most controversial discussions is the possible negative consequences of technology. Many different platforms discuss issues such as the positive and negative effects of children meeting technology at an early age, internet and internet addiction, and many science circles seem to be cautious about using technology. As a matter of fact, the internet usage has found to be related to the increasing loneliness and depression (Rajani and Chandio, 2004), the drop in academic success (Bayraktar and Gün, 2007) and weakening of family ties (Rajani and Chandio, 2004; Sook-Jung and Young-Gil, 2007). As the result of the study done with science teachers (Demirci Güler, Kaya ve Uzun, 2014), also showed that those teachers have similar concerns about using the internet as well. Disrupting students' attention and hosting harmful images for students are listed as problems with internet usage. There are also 
YYÜ Ĕ̆itim Fakültesi Dergisi (YYU Journal of Education Faculty), 2019; 16(1):620-647, http://efdergi.yyu.edu.tr

some concerns such as the fact that the Internet provides ready information for students and it leads to students' losing research skills (Açıkalın, 2009). 